\title{
INTEGRAÇÃO DO ENSINO E SERVIÇO DE ENFERMAGEM
}

\author{
Maria Isabel Santos*
}

RBE: $/ 03$

SANTOS, M. I. - Integração do Ensino e Serviço de Enfermagem. Rev. Bras. Enf.; Rio de Janeiro, 28: 60-70, 1975 .

\section{I — INTRODUÇÃO}

A integração de ensino e serviço na área da saúde de uma maneira geral, tem sido objeto de preocupação, não somente por parte dos que constituem o aparelho formador, como dos que fazem o aparelho utilizador.

Estes, com freqüência, alegam que os órgãos formadores encontram-se divorciados da realidade do País e que os seus planos curriculares não refletem as características dos modelos profissionais que os serviços de saúde necessitam (7).

Os educadores, por outro lado, não contam com a informação de uma política expressa em termos de planos de saúde que orientem a quantificação dos recursos humanos possíveis de serem absorvidos pelo setor saúde.

Esta lacuna, naturalmente, vem prejudicando os educadores quanto à utilização desses dados que constituem determinantes do currículo e clarificam o domínio das tomadas de decisões, impedindo, conseqüentemente a elaboração de planos que especifiquem o programa de educação de cada Faculdade (7) .

Particularmente a enfermagem, a separação entre ensino e serviço, vem acarretando dificuldades que crescem em complexidade com o passar do tempo, constituindo hoje, um problema sério tanto para as Escolas de Enfermagem como para o Serviço.

Di Lascio, ao examinar o processo de integração do enfermeiro recém-graduado na vida profissional, afirma que "ele está diretamente relacionado ccm o tipo de formação que, o enfermeiro recebeu na Escola". Entretanto, menciona estudos realizados que evidenciam divergências profundas entre educadores de enfermagem e enfermeiros de serviço quanto a concepção do papel do enfermeiro. Assim por exemplo, enquanto as enfermeiras de serviço centralizam o cuidado do paciente em torno do cumprimento de tarefas estabelecidas por normas e rotinas, as enfermeiras docentes ensinam que os cuidados de enfermagem devem ser individualizados, isto é, centralizados no paciente como pessoa una e total (4).

Face ao exposto não resta dúvidas de que o tema é polêmico, bastante complexo e seu equacionamento se reveste de real importância para alcançar um

* Professor adjunto da FENF, da UFPE e enfermeira de Saúde Pública. 
SANTOS, M. I. - Integraçăo do Ensino e Serviço de Enfermagem. Rev. Bras. Enf.; Rio de Janeïo, 28: 60-70, $1 \% i 5$.

denominador comum, visando o desenvclvimento da enfermagem quanto a elevação do padrão de assistência prestada à comunidade e a realização do ensino dentro de modelos mais realísticos.

\section{II - TENDENCIAS QUE FAVORECEM A INTEGRAÇÃO DO ENSINO E SERVIÇO}

\section{A Sociedade numa abordagem} sistêmica

O universo pode ser encarado como um conjunto integrado de sistemas de natureza diversa apresentando graus de complexidade.

Sistema, por definição, "é um conjunto de elementos que mantêm entre si um certo grau de integração e/ou interdependência e que está voltado para a realização de uma atividade" (3).

Os sistemas abertos tanto os simples como os complexos são constituídos basicamente dos seguintes elementos: sistema complexo uma vez que pode ser desdobrado em vários outros subsistemas tais como: educação, saúde, transporte, economia, comunicação e outros.

Caça um desses subsistemas embora atuando como uma unidade operacional independente dentro do sistema é intencionalmente selecionaco para realizar tarefas específicas a fim de que os objetivos globais do Sistema sejam alcançados. Dentro dessa abordagem, a integração dos diferentes subsistemas passa a ser encarada como uma propriedade do sistema. Neste caso, a integração de ensino e serviço torna-se uma condição imperiosa sob pena de caminharmos para o caos.

A título de exemplo apresentamos alguns modelos que ilustram as relações entre sistemas e subsistemas.

No MODELO 1, a sociedade é considerada o Sistema, cujas tarefas sociais a serem cumpridas são divididas entre os

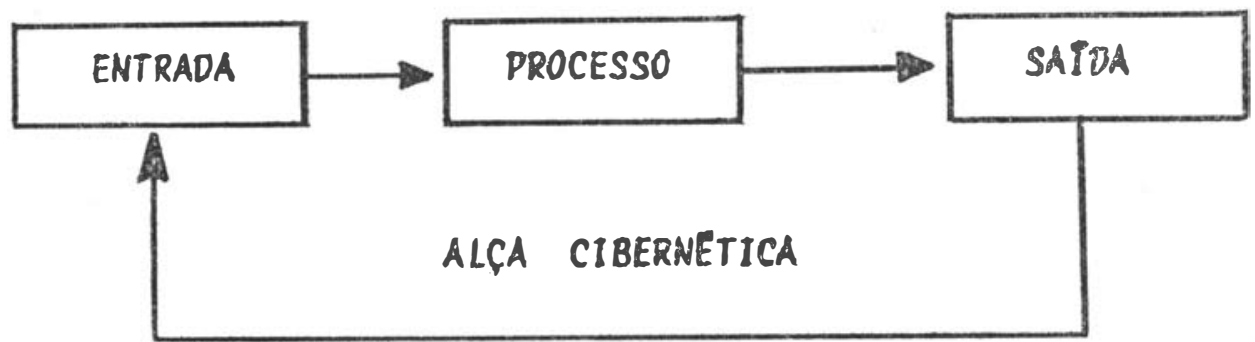

A ENTRADA é o aporte do meio exierno para o Sistema.

O PROCESSO são as operações realizacias dentro cio Sistema.

A SAÍDA é o aporte do Sistema para o meio externo.

A ALCGA CIBERNitidicA ou feed-bac!s é o dispositivo de autoconreção retroativa que tende a proteger o efeito da saída contra as variações dcs fatores da entrada.

Encarando a comunidade como um sistema social, constatamos que é um vários subsistemas, educação, saúde, economia e comunicação.

A eficiência co sistema ou melhor o grau de cumprimento dos objetivos prédeterminados vai depender do grau de reałização de cada um dos subsistemas mencionados, o que evidencia a interdepenciência dos mesmos.

Neste modelo, o setor saúde é considerado como um sistema em que o grau de eficiência vai depender da maneirr como os subsistemas alimentadores, isto é, aparelhos industrial e formador de pessoal realizam as suas tarefas quanto 
SANTOS, M. I. - Integração do Ensino e Serviço de Enfermagem. Rev. Bras. Enf.; Rio de Janeiro, 28: 60-70, 1 s.75.

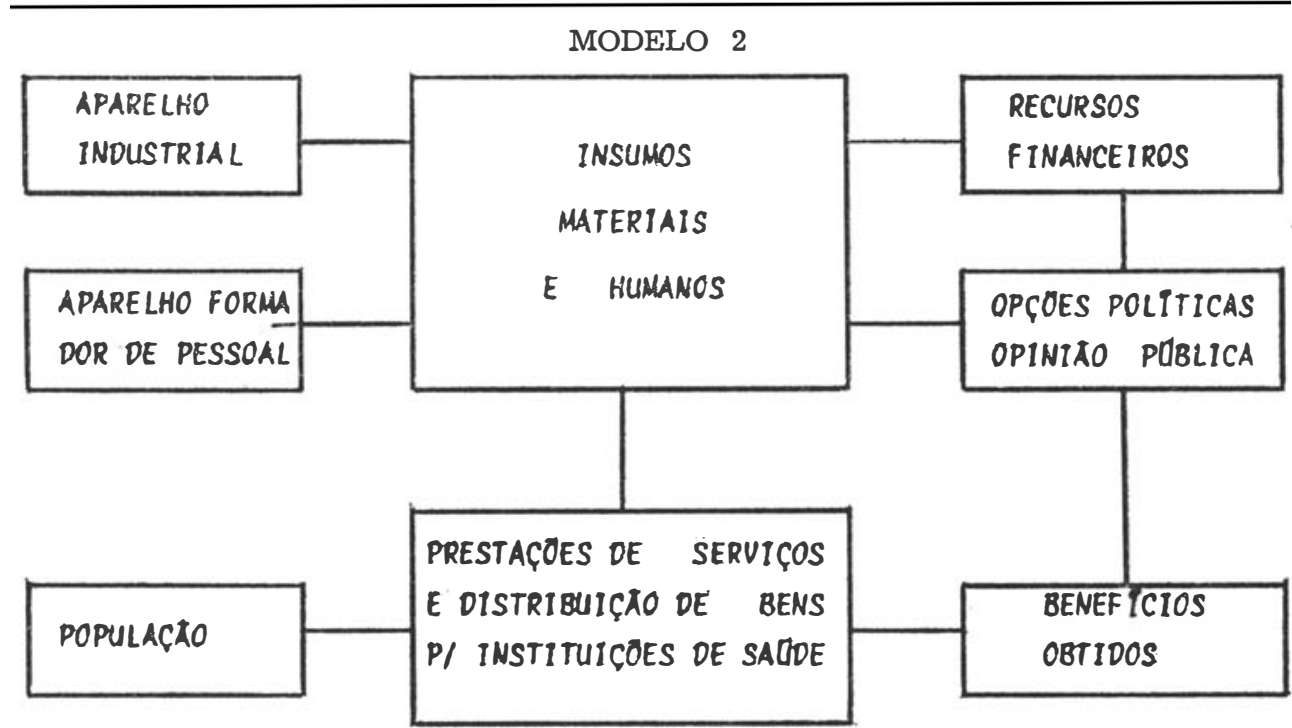

Modelo estrutural de un sistema de saüde.

\section{Fonte: CHAVES, Märio - Saüde e Sistemas. Rio de Janeiro, Fundação Getülio Vargas, 1992. $212 \mathrm{p}$.}

a produção de insumos materiais e hu.manos.

Por fim, depende ainda das limitações impostas, por um lacio, pelo sistema social no que se refere aos recursos financeiros que dispõe para atender as necessidades totais, e por outro lado, o quanto deste total, a sociedade está disposta a gastar com a saúde.

\section{Evolução do Conceito de Saúde}

O conceito de saúde tem sofrido ao longo do tempo alterações bastante significativas. De um conceito de saúde estático e baseado em atributos negativos isto é, saúde como ausência de doença, evoluiu para um conceito baseado em atributos positivos, isto é, "saúde como um completo bem estar físico, mental e social e não simplesmente ausência de doença (2). Segundo Brito Bastos, esta nova abordagem causa grande impacto nos Serviços de Saúde no que se refere. à integração das atividades preventivas e curativas, embora, do ponto de vista de mensuração ela ainda seja bastante falha. Hoje, entretanto, já se admite que saúde é uma condição dinâmica, isto é; depende de uma série de fatores de natureza diversa, daí, se definir saúcle como sendo um 'estado de harmonia entre as partes componentes do individu. entre o indivíduo, os membros de um sistema ecológico e entre o indivíduo e outros membros de um agregado social' (2).

Todos esses avanços levam os trabalhadores de saúde a concluir que saúde é apenas um dos componentes do nível de vida de um povo e, portanto, a melhoria do nível de saúde da comunidade depende da participação de outros setores.

3. Tendências em relação aos Serviços

Por muito tempo todas as atencões no campo da saúde estiveram voltadas para o aparelho formador. 
SANTOS, M. I. - Integração do Ensino e Serviço de Enfermagem. Rev. Bras. Enf.; Rio de Janeiro, 28: 60-70, 1675 .

Naturalmente, essa estratégia baseava-se na crença de que produzindo bons técnicos, e estes integrando-se ao Sistema, os serviços passariam por processo inovador. Infelizmente, porém, isto não ocorreu pelo menos, no nível desejado.

Os Serviços, ao longo dos anos foram perdendo em objetividade e eficiência.

Segundo o documento básico do Plano Decenal de Saúde para as Américas (1972-1982), "os programas assistenciais guardam uma herança de um sistema arcaico que foi de utilidade no passado. porém hoje em dia se caracteriza por limitada accessibilidade e insatisfação tanto do receptor como do doador" (6).

A insuficiência de cobertura das ações de saúde, contitui, hoje, o grande desafio para os que fazem saúde coletiva.

Vale mencionar ainda outra aspecto referido no citado documento de "que muitas vezes as motivações de prestação de serviços obedeceram a projetos que em lugar de partir das necessidades da comunidade, originaram-se do desejo de implantar técnicas e procedimentos importados, de benefícios duvidosos para as prioridades da sociedade" (6).

Em vista dessas e outras razões, o País está empenhado numa política de fortalecimento e adequação dos Serviços de Saúde às necessidades da comunidade. Para isto será necessário, realizar modificações substanciais nas estruturas tradicionais dos órgãos assistenciais e desenvolver pesquisas operacionais com o objetivo de explorar novos modelos assistenciais que permitam atender com $o$ menor custo o maior número de pessoas (6).

Para enfrentar este desafio, estão sendo convocados tanto o pessoal da área docente como o da área assistencial.

Resta-nos a tarefa de descobrir como fazer. Teoricamente existem inúmeras maneira, porém, somente o vivenciar de cada realidade poderá nos dizer qual o modelo mais adequado.
III - EXPERIENCIA DE INTEGRAÇÃO DE ENSINO E SERVIÇO DE ENFERMAGEM DE SAÚDE PÚBLICA DA ESCOLA DE ENFERMAGEM DA U.F.P.E.

\section{Justificativa}

A Escola de Enfermagem da Universidade Federal de Pernambuco, ao implantar o Curso de Enfermagem de Saúde Pública por força das reformas curriculares estabelecidas pelo Conselho Federal de Educação (Pareceres 271/62 e $163 / 72$ ), sentiu a necessidade de dispor de um Serviço de Saúde Pública que pudesse ser utilizado pelo docente e discente como laboratório das experiências de enfermagem, em ensino, assistência e pesquisa.

Várias alternativas foram propostas como solução para o problema, porém. optamos pela realização de um trabalho conjunto entre a Secretaria de Saúde do Estado e a Escola de Enfermagem pelas razões que passaremos a expor:

- As experiências anteriores realizadas com a criação de serviços isolados, demonstraram que dadas as características de laboratórios experimentais apresentaram padrões técnicos muits sofistivados, e, portanto difíceis de ser assimilados pela rede assistencial.

- A expansão de matrículas nas Universidades e a necessidade de expor os alunos a uma casuística mais representativa da estrutura nosológica local, exige que se utilize cada vez mais os serviços de Saúde da rede assistencial.

- A Secretaria de Saúde do Estado é o órgão a quem cabe, por força da Constituição, a responsabilidade de ditar a política de saúde a nível Estadual. Assim sendo, não somente dispõe de uma ampla rede assistencial com diferentes níveis de atenção como ainda é o principal empregador de recursos humanos para execução de programas na área da promoção e manutenção da saúde. 
SANTOS, M. I. - Integração do Ensino e Serviço de Enfermagem. Rev. Bras. Enf.; Rio de Janeiro, 28: 60-70, 1575.

- A Universidade de hoje dentre outras funções, desempenha um papel importantíssimo como órgão de vanguarda dentro da comunidade, quer no campo da pesquisa, criando o saber, quer na área de demonstração de novos métodos e técnicas assistenciais junto aos órgãos de saúde existentes.

- A presença de professores e estudantes em Serviços de Saúde extra Universidade, estimula a melhoria do padrão da assistência prestada à população, pelo papel que deverá exercer de agente de mudança na instituição.

- Por outro lado, o contato com a realidade possibilita aos professores e estudantes uma experiência que conduz a maior adequação de procedimentos técnicos e ensino dentro de padrões mais realistas.

\section{Desenho do Modelo Docente Assistencial}

Como a enfermagem é parte integrante cie um todo, o seu equacionamento depende necessariamente da estruturação de um modelo global de Saúce Pública. Em face disto foi constituído um grupo de trabalho representado por docentes da Escola de Enfermagem da Faculdade de Ciências Médicas da FESP e profissionais c'a Secretaria de Saúde. Como ponto de partida, o grupo procurou definir 10 modelo docente-assistencial estabelecendo as seguintes premissas básicas:

- Do ponto de vista da unidade de trabalho, é utilizada a área programática III da I Diretoria Regional do EStado de Pernambuco, situada em Recife, com uma população urbana de 300.000 habitantes.

- Do ponto de vista filosófico, o programa expressa o conceito de Saúde Pública como sendo o diagnóstico e o tratamento científico da comunidade.

- Do ponto de vista organizacional,
- modelo apresenta características de estrutura departamental com as funçōes de cada área claramente definidas em regimento e graficamente apresentadas no Funcionograma em anexo. A Direção do programa é necessariamente exercida por um docente /de Medicina e a Coordenação do Serviço de Enfermagem por um docente de Enfermagem.

- Do ponto de vista da estratégia geral da programação a área é divididia em setores e a assistência estruturada em diferentes níveis, isto é:

Domicílio-auto-cuidado:

Unidade tipo I - cuidados primários.

Unidade tipo II - cuidados especializados.

Unidade tipo III - internamento.

As ações de Saúde estão claramente definidas e quantificadas em termos de concentração e metas de cobertura em relação à população alvo.

Estão também normatizados o rendimento dos diferentes instrumentos destinados à produção das ações de saúde. Assim por exemplo: hora-médico, horaenfermeira, hora-visitadora, leito hospitalar e outros.

O programa conta com a participação de uma equipe multiprofissional coin papéis claramente definidos. Esta equipe overa predominantemente nas Unidades tipo II e III, exercendo as funções de docência, assistência e pesquisa. Aos níveis de autc-cuidado e cuidados primários, as ações de saúde são executadas predominantemente por pessoal auxiliar e a própria comunidade.

Faz parte ainda da estratégia, a delegação de funções como uma alternativa para aumentar a cobertura das ações de saúde à custos compatíveis com o nível de desenvolvimento econômico da região.

- Do ponto de vista docente, os programas aí desenvolvidos têm os seus objetivos operacionalizadcs e compatibilizados com as normas assistenciais. 
SANTOS, M. I. - Integração do Ensino e Serviço de Enfermagem. Rev. Bras. Enf.; Rio de Janeiro, 28: 60-70, $15^{\circ} 75$.

Desta forma, a integração da teoria e prática se faz de uma maneira bastante real pela plena utilização do princípio da prática equivalente. Neste caso, os ccmportamentos finais do estudante se confundem com os padrões de desempenho estabelecidos pelo Serviço para a categoria profissional específica.

- Do ponto de vista legal, os aparelhos utilizador e formador são partes celebrantes de um convênio no qual cabe ao primeiro, a responsabilidade de manutenção e, ao segundo, a execução do Plano de Saúde da área programática mencionada e ainda a docência.

\section{Implantação do Modelo Docente Assistencial}

Em iniciativa dessa natureza, todos nos sabemos que o planejamento do projeto não constitui problema, porém a sua implantação é que se apresenta como desafio. Por essa razão, preferimos, numa primeira fase, organizar o Serviço como um todo, e, somente quando esse estivesse estruturado, partir para modificação dos programas docentes. Dentro ciessa linha de ação, iniciamos o processo de implantação do modelo em questão em dezembro de 1973, com a organização dos serviços.

Embora não tenhamos ainda concluída a tarefa, várias etapas já foram vencidas, tais como: adequação quantitativa e qualitativa dos recursos humanos à nova metodologia assistencial; instalações das unidades periféricas encarregadas de prestar os cuidados primárics de saúde; adequação dos recursos materiais às necessidades dos programas em execução; normatização dos Serviços de pré-natal, assistência ao parto, puerpério, recém-nascido e à criança, segundo fluxograma em anexo; estabelecimento de um sistema de coleta de dados e informações de modo a permitir uma avaliação contínua o programa.
Estão em fase de estudos: a normatização dos Serviços de Epidemiologia, visitação domiciliar, saneamento ambiental e o programa de integração da comunidade, objetivando concretizar as metas dos programas de saúde.

Em relação à docência, este serviço está sendo usado como campo de prática para estudantes dos Cursos de Graduação de Medicina, Enfermagem, Nutrição e Serviço Social.

Quanto à metodologia de ensino, estamos ainda usando os padrōes convencionais, porém, está em fase de elaboração um projeto que objetiva o desenvolvimento de uma tecnologia educacional com vistas a uma maior racionalização das atividades docentes e participação do estuciante no processo de aprendizagem.

A Escola de Enfermagem da UFPE participa deste projeto, colocando à dispcsição do mesmo, em caráter permanente, um professor de tempo integral que exerce as funções de Assessoria; um professor de tempo parcial que exerce a função de Coordenação do Serviço de Enfermagem. Os demais docentes da. área em questão, atuam no programa, ora sob forma de Assessores para assuntos específicos, ora como profissionais integrantes da equipe de Saúde.

\section{IV - CONCLUSÕES}

A dissociação entre ensino e serviço na área da saúde forma um círculo vicioso que preocupa tanto ao pessoal da área da educação como da área assistencial.

Numa abordagem sistêmica da sociedade, saúde e educação são partes integrantes da mesma.

A integração entre snsino e serviço é encarada ccmo uma condição indispensável ao equilíbrio do sistema social na consecução dos seus objetivos.

Observa-se uma tendência em racio- 
SANTOS, M. I. - Integração do Ensino e Serviço de Enfermagem. Rev. Bras. Enf.; Rio de Janeiro, 28: 60-70, 1975.

nalizar o setor saúde e a formação dos recursos humanos através de um esforço conjunto dos órgãos assistenciais e de ensino.

A integração de ensino e Serviço de Enfermagem de Saúde Pública depende necessariamente da organização dos serviços de enfermagem que por sua vez estão condicionados à estruturação do Serviço de Saúde Pública como um todo.

E apresentado um modelo docenteassistencial como experiência local, numa cidade do Nordeste brasileiro, de integração de ensino e serviço.

\section{$\mathrm{V}$ - RECOMENDAÇÕES}

Que os órgãos formadores e assistenciais estudem as possibilidades de realizar um trabalho conjunto no sentido de implementar a criação de áreas-laboratórios que permitam testar não somente modelos assistenciais compatíveis com a realidade sócio-econômica e cul- tural da sociedade da qual fazem parte, mas, também, o desenvolvimento de uma tecnologia educacional dentro de padrões mais realistas.

Que os docentes tomem parte ativa no desenvolvimento dos programas assistenciais tanto à nível de prestação de assistência como à nível de decisão.

Que à medida que vão sendo estruturados os serviços, reformulem os programas docentes em função de definição de objetivos comportamentais que conduzam os estudantes à utilização de esquemas de ação que favoreçam a criatividade, e a capacidade de crítica.

Que sejam incentivadas pesquisas visando incrementar o conhecimento da enfermagem e melhor padrão assistencial da comunidade.

Que a administração dos órgãos docentes encarem o trabalho de manutenção dos campos de estágio como atividade inerente ao trabalho docente.

\section{BIBLIOGRAFIA}

1. ALVAREZ MANILLA, José Manuel Metodologia de la enseñanza de la Medicina en el futuro. Educación Médica u Salud, Washington, 8 (2): 152-157. 1974.

2. BASTOS, Brito - Evolução do Conceito de Saúde. In: Política Nacional de Saúde. Rio de Janeiro, Artes Gráficas da Divisão de Administração da Fundação Serviço de Saúde Pública, p. 1-40, 1971.

3. CHAVES, Mário - Saúde e Sistemas. Fundação Getúlio Varbas, Rio de Janeiro, p. 212. 1972.

4. DI LASCIO, Cecília Maria Domenica Sanioto - Integração do recémgraduado na vida profissional. Revista Brasileira de Enfermagem. Rio de Janeiro, 23 (3/6): 57-72. 1970.
5. FERREIRA, José Roberto - Las ciencias fisiológicas en la formación del médico. Educación Médica y Salud, Washington, 9 (1): 74-87. 1975.

6. ORGANIZAÇAO MUNDIAL DA SAÚDE - Plan decenal de Salud para las Americas, Washington, 1973. p. 145 (Documento Oficial, 118).

7. ORGANIZAÇAO MUNDIAL DA SAÚDE - Planificación de los recursos de personal de salud en las Américas. Cronica de la OMS, Ginebra, 29 (3) : 89-95. 1975.

8. SEMINARIO sobre integração de ensino e serviço de enfermagem em Hospitais Universitários, Universidade Federal da Bahia, Salvador, p. 137. 1969. 
SANTOS, M. I. - Integração do Ensino e Serviço de Enfermagem. Rev. Bras. Enf.; Rio de Janeiro, 28: 60-70, 15. 75 .

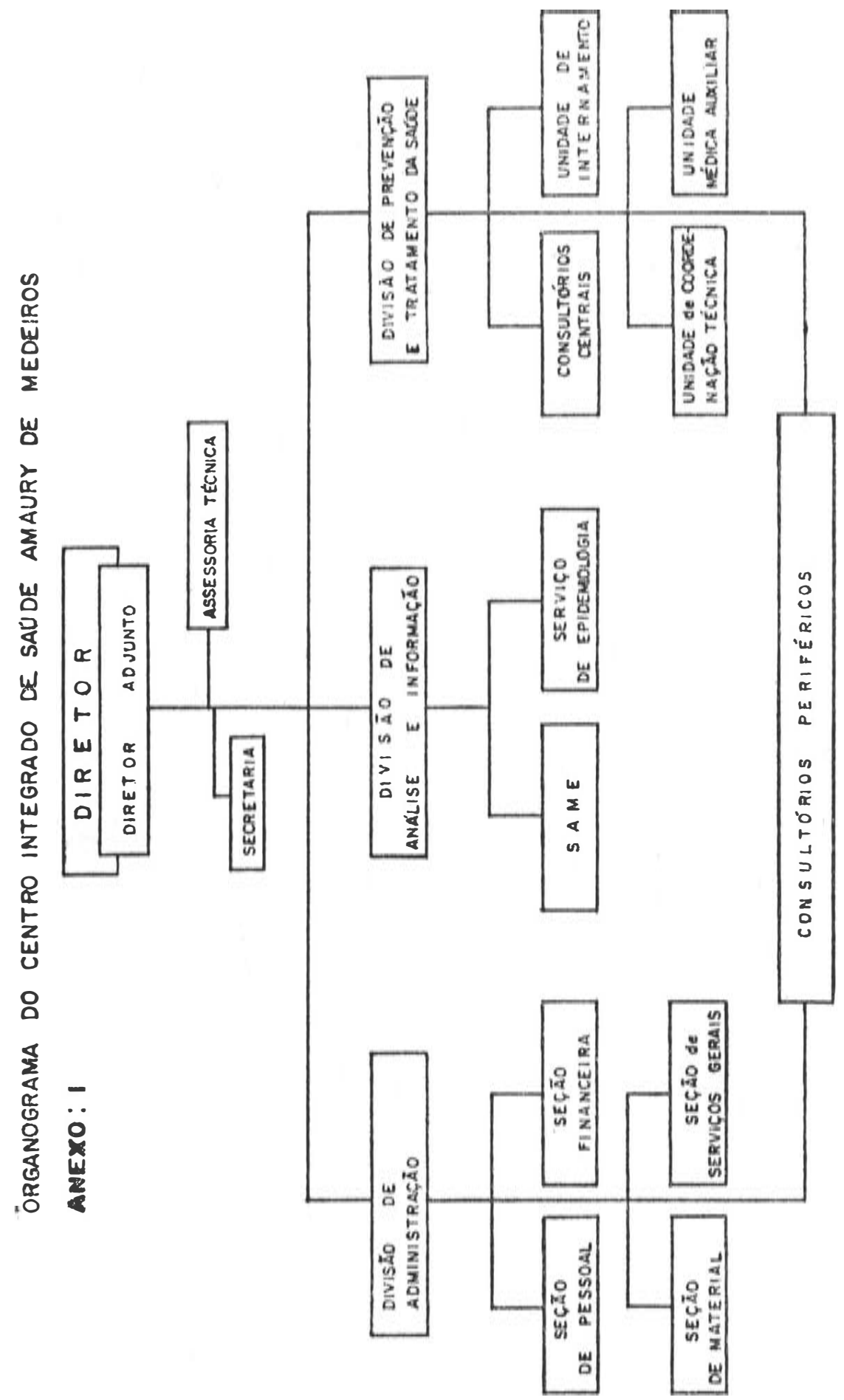




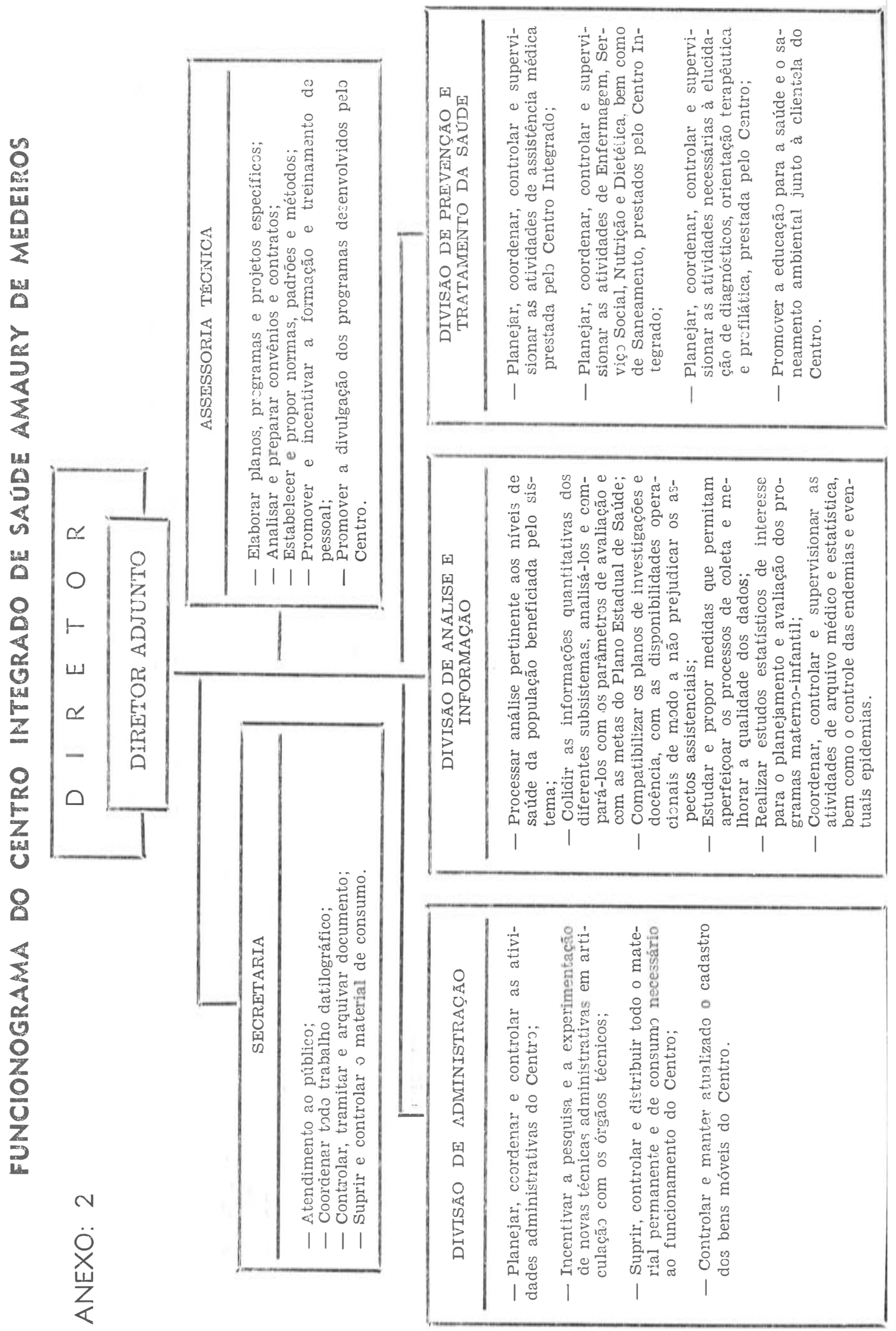




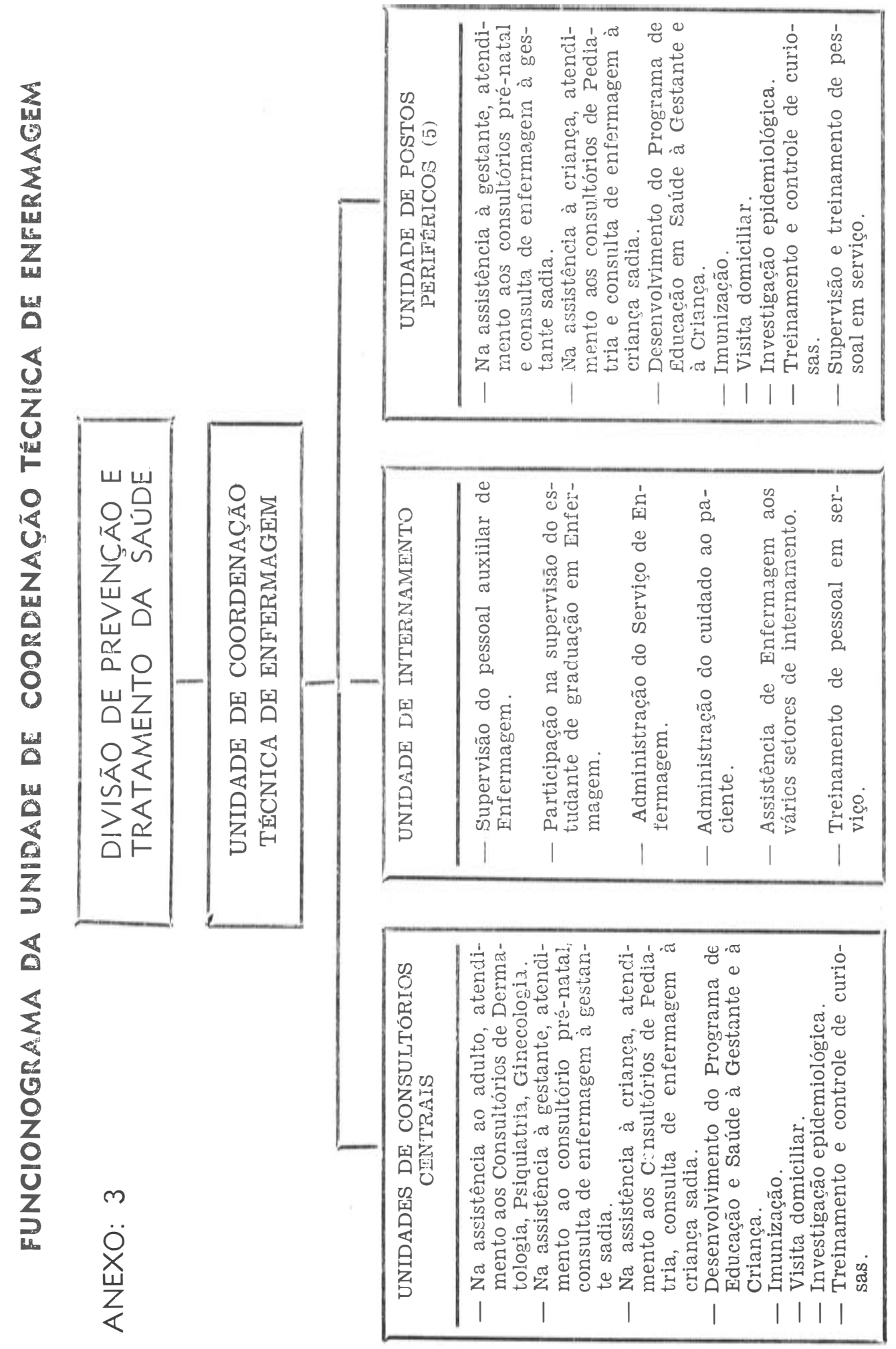


SANTOS, M. I. - Integração do Ensino e Serviço de Enfermagem. Rev. Bras. Enf.; Rio de Janeiro, 28: 60-70, 1975.

FLUXOGRAMA DO CISAM

AHEXO: 9

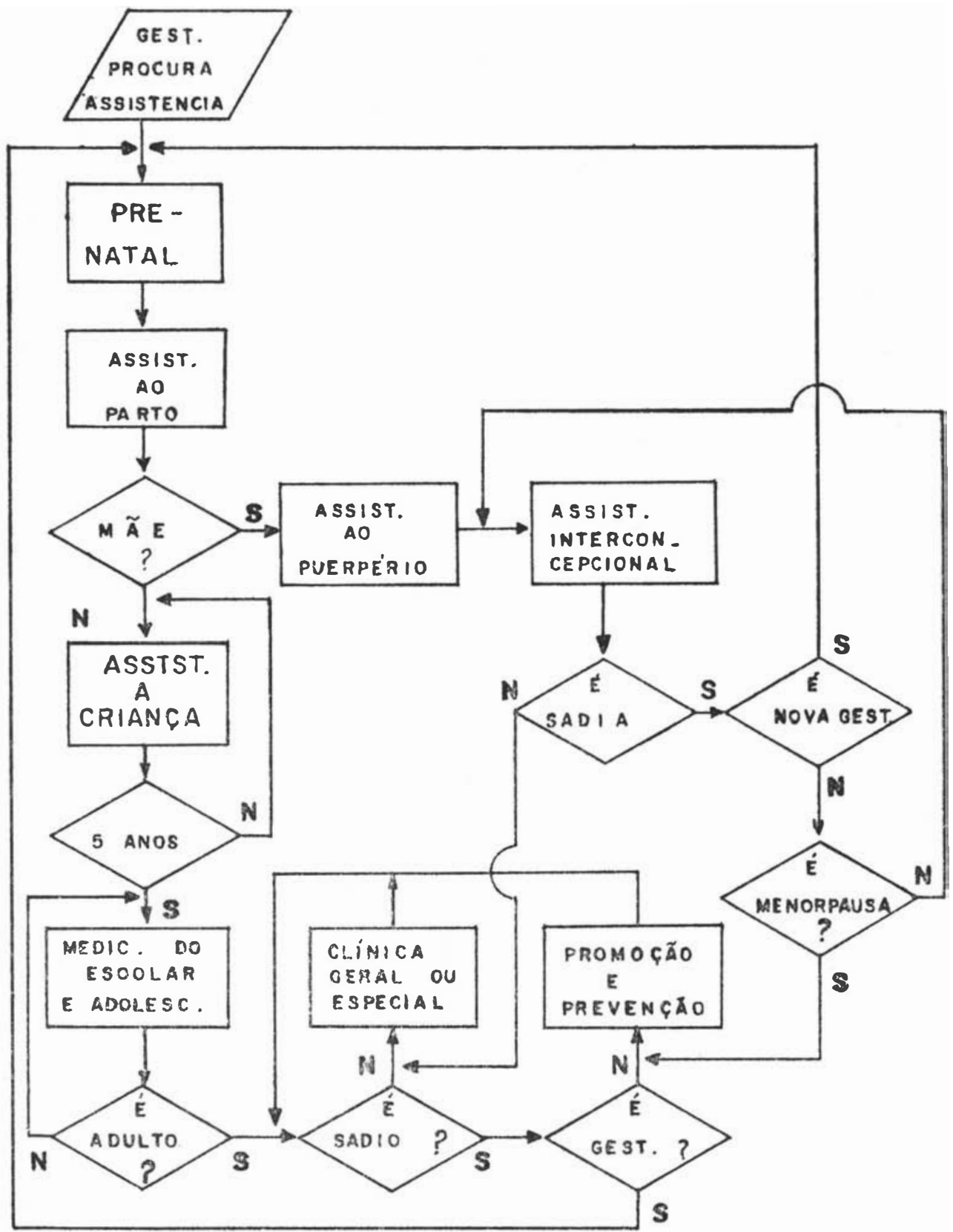

